\title{
Consequences of IDH1/2 Mutations in Gliomas and an Assessment of Inhibitors Targeting Mutated IDH Proteins
}

\author{
Bozena Kaminska ${ }^{1, *}\left(\mathbb{0}\right.$, Bartosz Czapski ${ }^{1,2,4}$, Rafal Guzik ${ }^{1,3}$, Sylwia Katarzyna Król ${ }^{1}(\mathbb{D}$ and \\ Bartlomiej Gielniewski ${ }^{1}$ \\ 1 Laboratory of Molecular Neurobiology, Nencki Institute of Experimental Biology of the Polish Academy of \\ Sciences, 02-093 Warsaw, Poland; bartolomeo.capellini@gmail.com (B.C.); r.guzik@nencki.gov.pl (R.G.); \\ s.krol@nencki.gov.pl (S.K.K.); b.gielniewski@nencki.gov.pl (B.G.) \\ 2 Postgraduate School of Molecular Medicine, Medical University of Warsaw, 02-093 Warsaw, Poland \\ 3 Department of Biochemistry, Faculty of Medicine and Health Sciences, Andrzej Frycz Modrzewski Krakow \\ University, 30-705 Krakow, Poland \\ 4 Department of Neurosurgery, Mazovian Bródnowski Hospital, 03-242 Warsaw, Poland \\ * Correspondence: b.kaminska@nencki.gov.pl; Tel.: +48-22-5892209; Fax: +48-22-8225342
}

Academic Editor: Silvia Schenone

check for Received: 3 February 2019; Accepted: 4 March 2019; Published: 9 March 2019

\begin{abstract}
Isocitrate dehydrogenases (IDH) 1 and 2 are key metabolic enzymes that generate reduced nicotinamide adenine dinucleotide phosphate (NADPH) to maintain a pool of reduced glutathione and peroxiredoxin, and produce $\alpha$-ketoglutarate, a co-factor of numerous enzymes. IDH1/2 is mutated in $~ 70-80 \%$ of lower-grade gliomas and the majority of secondary glioblastomas. The mutant IDH1 (R132H), in addition to losing its normal catalytic activity, gains the function of producing the D-(R)-2-hydroxyglutarate (2-HG). Overproduction of 2-HG in cancer cells interferes with cellular metabolism and inhibits histone and DNA demethylases, which results in histone and DNA hypermethylation and the blockade of cellular differentiation. We summarize recent findings characterizing molecular mechanisms underlying oncogenic alterations associated with mutated IDH1/2, and their impact on tumor microenvironment and antitumor immunity. Isoform-selective IDH inhibitors which suppress 2-HG production and induce antitumor responses in cells with IDH1 and $I D H 2$ mutations were developed and validated in preclinical settings. Inhibitors of mutated IDH1/2 enzymes entered clinical trials and represent a novel drug class for targeted therapy of gliomas. We describe the development of small-molecule compounds and peptide vaccines targeting IDH-mutant gliomas and the results of their testing in preclinical and clinical studies. All those results support the translational potential of strategies targeting gliomas carrying IDH1 mutations.
\end{abstract}

Keywords: IDH mutations; metabolic disturbances; epigenetics; gliomas; tumor microenvironment; IHD mutant inhibitors

\section{Functions of Isocitrate Dehydrogenases}

Since the initial discovery of mutations in the isocitrate dehydrogenase 1 (IDH1) gene by whole-genome sequencing in a large subset of human gliomas [1], and in acute myelogenous leukemia (AML) [2], much interest was focused on understanding consequences of mutations in IDH genes and their roles in tumor progression. Isocitrate dehydrogenases 1 and 2 are key Krebs cycle enzymes that are nicotinamide adenine dinucleotide phosphate $\left(\mathrm{NADP}^{+}\right)$-dependent and catalyze the oxidative decarboxylation of isocitrate to $\alpha$-ketoglutarate ( $\alpha$-KG). There are three IDH isoforms, IDH1, IDH2, and IDH3, encoded by different genes. NADP-dependent IDH1 and IDH2 share considerable sequence similarity $(70 \%)$ and an almost identical protein structure [3]. IDH3 has a unique sequence, is a 
NAD-dependent enzyme [4], and plays a central role in energy production. To date, there are no reports of tumor-associated mutations in the IDH3 gene. IDH1 mainly occurs in the cytoplasm and peroxisomes, while IDH2 and IDH3 are found in the mitochondrial matrix [5]. IDH1/2 proteins catalyze the oxidative decarboxylation of isocitrate to $\alpha-\mathrm{KG}$ to produce reduced nicotinamide adenine dinucleotide phosphate (NADPH) from NADP ${ }^{+}$. IDH1 and IDH2 enzymes maintain an adequate pool of reduced glutathione (GSH) and peroxiredoxin by providing NADPH. This maintains redox balance, protecting the cell against oxidative damage from various cellular stressors. NADPH generated by IDH1 is involved in lipid metabolism [6] and contributes to the cellular defense against reactive oxygen species (ROS) induced during lipid oxidation [7]. IDH1 and IDH2 participate in protection from oxidative stress [8] by producing molecules such as NADPH and $\alpha-K G$ which have strong reductive properties and protect against DNA damage via their interactions with glutathione- and thioredoxin-producing systems [9]. The reaction driven by IDH1 is the main source of NADPH in the human brain, producing as much as $65 \%$ of the brain's NADPH [10]. IDH1 and IDH2 are also involved in glutamine metabolism under hypoxia and electron transport chain alterations [11].

\section{Pathophysiology of Isocitrate Dehydrogenase Mutations}

High-density oligonucleotide arrays and next-generation sequencing of glioma samples of grades II and III (according to classification of the World Health Organization, WHO) revealed an unexpected spectrum of mutations, among which somatic, recurrent mutations in the IDH1 gene were found in $12 \%$ of glioma samples [1]. IDH mutations occur early in pathogenesis of gliomas and persist throughout progression of a glioma from a neural stem or progenitor cell. All known IDH mutations are invariably monoallelic. Mutations in IDH1 and IDH2 genes are mostly missense variants leading to a single amino-acid substitution of arginine residues at codon 132 in exon 4 of the IDH1 gene or codons 140 or 172 of the IDH2 gene (IDH1-R132, IDH2-R140, or IDH2-R172). IDH1-R132 mutants have dominant-negative, inhibitory effects on wild-type IDH1 (IDH1-wt) in vitro [12].

In addition to losing its catalytic activity, mutant IDH1 and IDH2 enzymes gain the function of catalyzing the reduction of $\alpha$-ketoglutarate (KG) to its $(R)$-enantiomer of 2-hydroxyglutarate (2-HG) [13]. The 2-HG compound has properties of an oncometabolite, and its accumulation in the cell contributes to cancerogenesis [14]. An oncometabolite is typically a small molecule (or enantiomer), which participates in normal metabolism, but whose accumulation causes metabolic deregulation and, consequently, predisposes cells for future progression to cancer. This term is assigned to $R(-)-2-$ hydroxyglutarate $((R)-2 \mathrm{HG})$. The 2-HG compound adopts almost identical location to $\alpha-\mathrm{KG}$ at the catalytic sites of DNA hydroxylases and enzymes containing the Jumonji domain. 2-HG is most potent against JMJD-containing histone demethylases (JMJD2A, JMJD2C, and FBXL11) with IC 50 values of approximately $100 \mu \mathrm{M}$, suggesting that the JMJD-containing histone demethylases, which includes nearly 30 distinct enzymes in mammalian cells, are probably the main target of 2-HG inhibition. Accumulation of 2-HG in cancer cells results in the complete inhibition of Jumonji-class histone demethylases $[15,16]$. Changes in histone methylation profiles (especially H3K9 methylation) are associated with IDH mutations and result in inhibition of cell differentiation [17]. Moreover, 2-HG is a competitive inhibitor of the ten-eleven translocation (TET) family of 5-methlycytosine hydroxylases responsible for the demethylation of DNA [18,19] (Figure 1). 


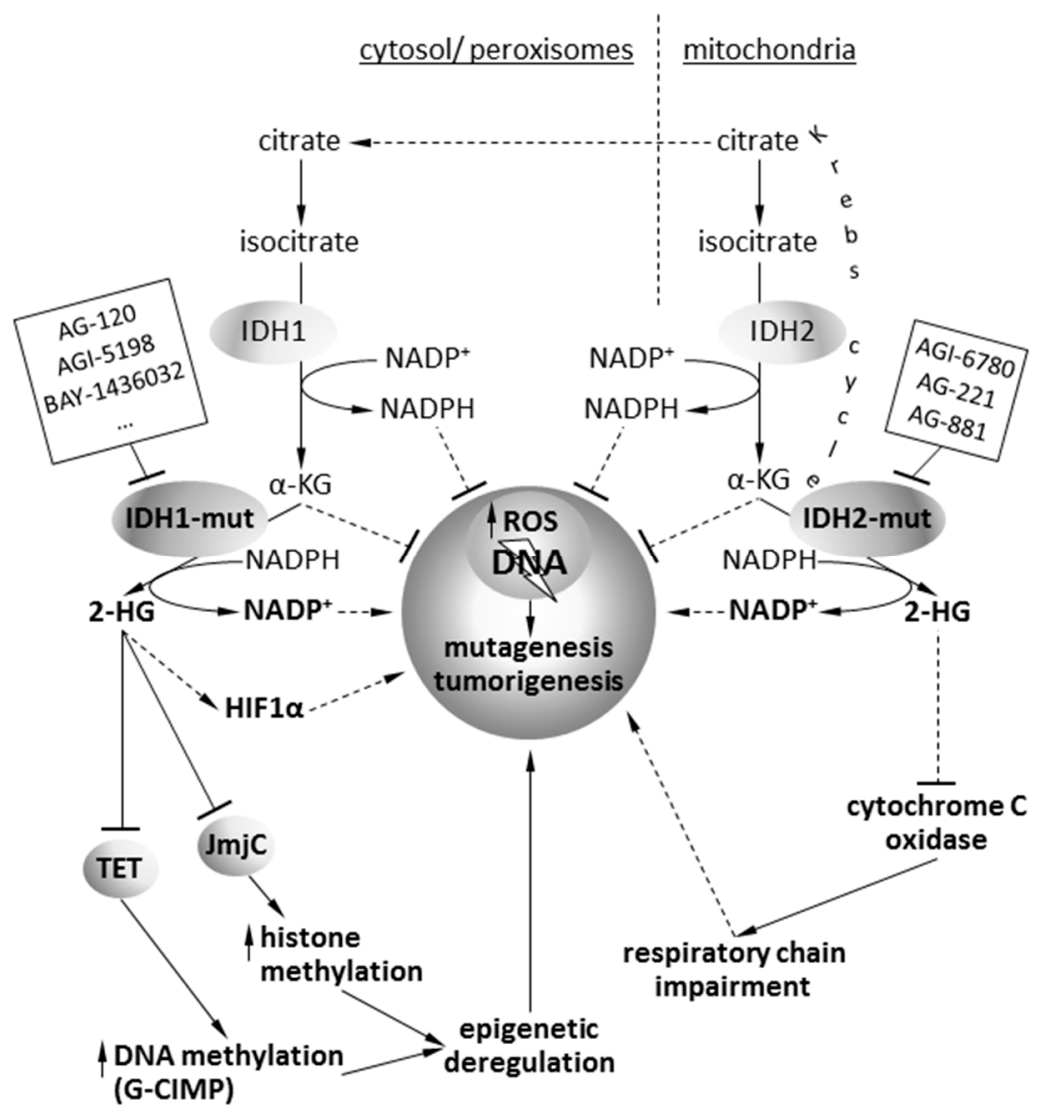

Figure 1. Summary of metabolic and epigenetic alterations induced by IDH mutations in cancer cells. The action mode of inhibitors targeting the mutant isocitrate dehydrogenase (IDH) proteins is indicated.

A high concentration of 2-HG also promotes angiogenesis via inhibition of prolyl-hydroxylases and stabilization of hypoxia-induced factor $(\mathrm{HIF} 1 \alpha)$, a transcription factor which controls genes promoting cell adaptation to hypoxia, i.e., vascular endothelial growth factor (VEGF) [12]. High HIF1 $\alpha$ expression was found in $15 \%$ of IDH-mutant (IDH-mut) tumors compared to $7.7 \%$ of $I D H$-wt tumors [9]. More detailed studies revealed that $I D H$ mutation status is associated with a distinct angiogenesis transcriptome signature, decreased expression of HIF1 $\alpha$ targets, and impairment of downstream biological functions such as angio- and vasculogenesis that are critical for tumor growth [20].

IDH mutations cause profound changes in global cellular metabolism. Initial studies of the effect of IDH mutations on the tricarboxylic acid (TCA) cycle function failed to demonstrate significant alterations in TCA cycle metabolites [14]. However, a more detailed study by Reitman et al. [21], who profiled $>200$ metabolites in IDH1- or IDH2-mut oligodendroglioma cells, detected changes in levels of amino acids, glutathione metabolites, choline derivatives, and tricarboxylic acid cycle intermediates. These changes mimicked those identified after treatment of the cells with 2-HG. $\mathrm{N}$-Acetyl-aspartyl-glutamate (NAAG), a common dipeptide in brain, was 50-fold reduced in IDH1-mut expressing cells and 8.3-fold reduced in IDH2-mut expressing cells. A similar reduction of NAAG was detected in IDH-mut glioma tissues [21]. Acetyl coenzyme A (CoA), which is generated from citrate in the cytoplasm, was shown to regulate the acetylation of cytoplasmic proteins. $I D H$-mut tumors exhibit perturbed acetyl-CoA metabolism and reduced cytosolic acetyl-CoA concentrations, which may result in altered acetylation and activity of many tumorigenic proteins [22]. IDH1-mut cells shared multiple metabolic changes with 2-HG-treated cells, suggesting that the oncometabolite production is responsible for the observed metabolic effects [14].

IDH1 activity is also an important factor in metabolic adaptation, which supports an aggressive growth of primary glioblastomas (GBM) maintained despite difficult metabolic conditions. Primary GBMs develop de novo and are the most malignant brain tumors. A wild-type IDH1 mRNA (messenger 
RNA) and protein are commonly overexpressed in primary GBMs and increased IDH1-wt activity was found in $65 \%$ of those tumors. Genetic and pharmacological inactivation of IDH1 decreased GBM cell growth, promoted more differentiated phenotype, increased apoptosis in response to targeted therapies, and prolonged survival of animals with patient-derived xenografts. This forced IDH inactivation/inhibition was accompanied by reduced $\alpha-K G$ and NADPH levels, increased ROS production, enhanced histone methylation, and increased expression of differentiation markers [23]. This suggests that IDH1 upregulation represents a metabolic adaptation of GBM to support growing demands of macromolecular synthesis in tumor cells.

\section{Detection of IDH Mutations Improves Classification of Gliomas and Predicts Better Survival}

Gliomas are primary tumors of the central nervous system (CNS) that originate from transformed neural stem or progenitor glial cells, and they were divided by the World Health Organization (WHO) into low-grade gliomas (LGG, WHO grades I and II) and high-grade gliomas (HGG, WHO grades III and IV). LGG are well-differentiated, slow-growing tumors, whereas HGG are less differentiated or anaplastic and diffusive, strongly infiltrating brain parenchyma and making a surgical resection difficult. Histological classification is currently assisted by molecular genetic studies that provide diagnostic, prognostic, and predictive values, and an IDH genotype was recently added as the one of the key molecular factors to the classification of gliomas. The new 2016 WHO classification scheme divides diffuse gliomas into LGGs and glioblastomas (GBMs) based on histology. LGGs are further divided into $I D H$ wild type or mutant, which is further classified into either an oligodendroglioma that harbors $1 \mathrm{p} / 19 \mathrm{q}$ co-deletion or a diffuse astrocytoma that has an intact $1 \mathrm{p} / 19 \mathrm{q}$ loci, but is enriched for ATRX and TP53 mutations [24].

According to recent WHO classification glioblastomas are divided into an IDH-wt GBM, which corresponds to a primary or de novo GBM, and an IDH-mut GBM, which refers to a secondary or progressive GBM. A mutation in IDH1 is sufficient to induce genome-wide changes in DNA methylation patterns, including the glioma cytosine phosphate guanine $(\mathrm{CpG})$ island methylator phenotype (G-CIMP) found in a subset of gliomas, which is associated with diverse transcriptional changes [17,25]. G-CIMP is characterized by hypermethylation of CpG islands. Among IDH-mut astrocytomas, methylation profile clustering can further subdivide these tumors into G-CIMP-low and G-CIMP-high, reflecting low or high DNA methylation with a significant difference in survival. DNA methylation studies provided an evidence that G-CIMP-high tumors may in fact progress to those that are G-CIMP-low [26]. DNA methylation patterns in IDH-mut GBMs are distinct from lower-grade astrocytomas [27]. The identification of clinically relevant subsets of G-CIMP tumors (G-CIMP-high and G-CIMP-low) provided a further refinement in glioma classification that is independent of grade and histology. Many studies showed that patients with IDH-mut gliomas have better survival compared to their IDH-wt counterparts irrespective of histology and grade, making IDH mutation the most important prognostic factor for survival, followed by age, tumor grade, and $\mathrm{O}^{6}$-methylguanine-DNA methyltransferase gene (MGMT) status (reviewed in Reference [28]). Clinical statistics show that a median overall survival (OS) is 31 months for secondary GBM patients with IDH mutations compared to 15 months for those without the mutations. Patients with IDH-mut anaplastic astrocytoma have 65 months of median OS compared to 20 months in their IDH-wt counterparts [29]. The presence of IDH1 mutations in anaplastic oligodendroglioma patients is a very strong prognostic factor for OS, but has no a predictive significance for outcome to PCV chemotherapy (adjuvant procarbazine, 1-(2-chloroethyl)-3-cyclohexyl-1-nitrosourea, and vincristine) [30]. All reasons for which glioma patients with IDH1 mutations show better therapeutic responses and longer survival remain unclear.

Almost $100 \%$ of tumors of oligoastrocytic and oligodendrocytic origin harbor IDH1/2 mutations; up to now, there is no evidence of any mutations in IDH3 in glial tumors [29]. IDH1/2 mutations were found in a majority of secondary GBMs (derived from lower-grade tumors) [29], but only 2-3\% were 
found in primary GBMs [31] or pediatric gliomas [32]. IDH mutations are considered to be the primary initiating event in WHO grade II/III gliomas and secondary GBMs [33].

Several concepts were conceived to explain how IDH mutations influence patient outcome. It is believed that decreased MGMT expression, caused by the MGMT gene promoter methylation, has a major influence on GBMs responsiveness to alkylating agent therapy (i.e., temozolomide, TMZ) [34]. $I D H$ mutations occur more frequently in young patients (younger age of diagnosis) with WHO grade II/III gliomas, who have generally better prognosis [29,35]. However, the IDH1 mutation does not directly or always correlate with patient survival. Among adult GBM patients who survived at least 36 months, less than one-quarter of them were associated with the IDH1-mut status [36]. However, the presence of IDH1 mutation was a weak prognostic factor in GBM patients with a long-term survival [37]. Also, in the case of low-grade oligodendroglial tumors, the mutation in IDH1 was not a prognostic factor. While $91 \%$ of oligodendrogliomas harbored the IDH1 mutation, the survival times of patients with IDH1-mut tumors were not different compared to patients with IDH1-wt tumors. Patients with IDH1-mut diffuse astrocytomas lived significantly longer. This suggests that IDH mutations could be a prognostic factor for diffuse astrocytoma, but not for oligodendroglioma [38].

Several reports pointed out that prognosis for glioma patients with the IDH1 mutation is associated with DNA methylation patterns. There is a subtype of glioma characterized by the presence of the IDH mutation and a low level of DNA methylation (G-CIMP-low) which was associated with a poor outcome [26]. Additionally, the impact of IDH1 mutations for patient survival may depend on other factors, such as alterations in 1p/19q, ATRX, PTEN, or MGMT methylation status [39,40]. Ki-67 expression in combination of IDH-mut may also influence patient survival. Patients with IDH1/2-mut and a low level of Ki-67 expression had a relatively good prognosis, while patients with IDH1/2-mut and a high level of Ki-67 expression had significantly worse prognosis and shorter times of survival [41]. Outcome of patients with IDH mutation was also associated with the occurrence of copy number alterations (CNAs). Patients characterized by the presence of one of the CNAs, $+7 q,+8 q,-9 p$, or $-11 p$, were associated with worse prognosis and worse overall survival when compared to other patients with the IDH mutation [42]. Additionally, prognosis and time of survival of patients with the IDH mutation may be gender-dependent; the presence of the IDH1 mutation was associated with a longer time of survival in male, but not in female patients [43].

While the presence of IDH mutations commonly correlates with better outcome of glioma patients, some studies showed the connection between the presence of IDH mutation and seizure risk in glioma patients. A majority of patients with WHO grade II astrocytoma (but not GBM) suffered pre-operative seizures related to the presence of $I D H$ mutation [44]. A recent meta-analysis confirmed that the presence of IDH1 mutation is correlated with the higher number of preoperative seizures in LGG [45].

\section{Impact of IDH Mutations on Glioma Microenvironment}

The microenvironment of gliomas is heterogeneous, and there are numerous cancer and non-cancerous, stromal cells which dynamically interact with themselves and with an extracellular matrix. In glioblastoma, this microenvironment includes reactive astrocytes, endothelial cells, and many types of immune cells, among which a main component (up to $30 \%$ of a tumor mass) are glioma-associated microglia and macrophages. This population is composed of brain-resident microglia, infiltrating, blood-derived macrophages, and myeloid-derived suppressive cells. Tumor-derived molecules attract and reprogram infiltrating microglia and macrophages and convert them into the cells that support invasion and produce local and systemic immunosuppression (for a review, see References [46,47]).

Recent studies provided emerging insights into how IDH mutations affect the glioma microenvironment. Cytotoxic T lymphocytes $\left(\mathrm{CD}^{+}\right.$, cluster of differentiation 8 positive) are crucial components of the tumor-specific adaptive immunity. Lymphocyte infiltration occurs to some extent in glioma, and the presence of tumor-infiltrating lymphocytes (TILs) is predictive of clinical outcome [48,49]. The number of CD8 ${ }^{+}$TILs was inversely correlated with tumor grade, whereas the number of $\mathrm{CD}^{+}{ }^{+}$TILs was positively correlated with tumor grade. $\mathrm{FoxP}^{+}$(forkhead box P3) regulatory 
lymphocytes were observed only in GBMs [50]. The extent of local glioma-associated CD8 ${ }^{+} \mathrm{T}_{\text {-cell }}$ infiltrate at initial presentation correlates with the long-term survival of GBM patients [51]. The immune checkpoint molecules such as CTLA-4 (cytotoxic T cell antigen 4), PD-1 (Programmed cell death protein 1), PD-L1/2 (Programmed death-ligand 1/2) and others provide inhibitory signals to $\mathrm{T}$ cells [52]. In glioma patients, the accumulation of $\mathrm{CD}^{+} / \mathrm{CD}^{+} \mathrm{T}$ cells and $\mathrm{T}$ regulatory cells (Tregs) that express high levels of CTLA-4 and PD-1, or the high expression of PD-L1 in glioma cells correlates with WHO high grade and short survival [53,54]. The impact of IDH mutations on immune microenvironment is under debate. Analyses of clinical samples and gene expression data from The Cancer Genome Atlas (TCGA) demonstrated reduced expression of cytotoxic T-lymphocyte-associated genes and interferon (IFN)- $\gamma$-inducible chemokines (i.e., CXCL10) in IDH-mutant tumors compared with IDH-wt tumors. Introduction of mutant IDH1 or treatment with 2-HG reduced levels of a chemokine CXCL (C-X-C motif) 10, which was associated with decreased expression of a transcription factor STAT1 (signal transducer and activator of transcription 1), an inducer of inflammation. Forced expression of a mutant IDH1 also suppressed the accumulation of $\mathrm{T}$ cells at tumor sites. Those events were reversed by IDH-C35, a specific inhibitor of a mutant IDH1 [55].

A single study showed that IDH1 mutation did not associate with increased intratumoral expression of either PD-1+ TIL or PD-L1 in GBMs [56]. However, a recent study demonstrated that IDH-wt is associated with the significantly higher TIL infiltration and PD-L1 expression among all grade II-IV gliomas and within the cohort of GBMs [57]. In LGGs and GBMs of TCGA cohorts, significantly higher PD-L1 gene expression was found in IDH-wt compared with IDH-mut tumors. Lower PD-L1 gene expression was associated with the increased promoter methylation in the LGG cohort of TCGA. IDH-mut gliomas had higher PD-L1 gene promoter methylation levels than IDH-wt gliomas [57]. PD-L1 expression was significantly associated with a worse clinical outcome in primary and recurrent $I D H$-wt GBMs [58]. As IDH1-wt gliomas exhibit increased PD-L1 expression and greater TIL infiltration, those tumors are considered to be more immunologically active and more susceptible to immunomodulatory therapy against PD-1/PD-1L than IDH-mut gliomas. Those observations underlie the importance of evaluating IDH1/2 status in immunomodulatory therapies.

A flow cytometry analysis of immune composition of human gliomas with a different IDH1 status demonstrated that human IDH1-mut gliomas have significantly lower infiltration of CD45 ${ }^{+}$ immune cells, including microglia, macrophages, dendritic cells, B cells, and T cells, compared with IDH1-wt gliomas. The downregulated genes in IDH1-mut gliomas were associated with immune system processes, and the major Gene Ontology terms were related to chemotaxis and immune cell migration [59]. Introduction of IDH1-mut into transgenic mouse gliomas with different genetic background, expressing platelet-derived growth factor alpha (PDGF $\alpha$ ), shp53, or Ink4a/Arf ${ }^{+/+}$and Ink4a/Arf ${ }^{+/-}$, demonstrated significantly shorter survival compared to mice with IDH1-wt tumors. Similar to human IDH1-mut gliomas, reductions in $\mathrm{CD} 45^{+}$cells, including microglia, macrophages, monocytes, and polymorphonuclear leukocytes, were reported in the IDH1-mut murine tumors. Gene expression in IDH1-mut mouse gliomas was negatively associated with leukocyte and neutrophil migration [60]. A computational analysis of relative immune cell content and type of immune response in subtypes of GBMs in the TCGA RNA-sequencing dataset was carried out. All G-CIMP and IDH1-mut GBMs were characterized by negative immune responses and lower human leukocyte antigen (HLA) expression [61]. The analyses of complement activation and $\mathrm{CD}^{+}, \mathrm{CD}^{+}$, or FoxP3 ${ }^{+} \mathrm{T}$-cell infiltration in sections from 72 gliomas of WHO grade III and IV with or without IDH mutations showed significantly reduced complement activation and decreased numbers of tumor-infiltrating $\mathrm{CD}^{+}$and $\mathrm{CD} 8^{+} \mathrm{T}$ cells with comparable FoxP3 ${ }^{+} / \mathrm{CD}^{+}$ratios. Ex vivo studies demonstrated that $2-\mathrm{HG}$ inhibits complement activation, decreases cellular $\mathrm{C} 3 \mathrm{~b}(\mathrm{iC} 3 \mathrm{~b})$ opsonization and complement-mediated phagocytosis, and inhibits T-cell migration, proliferation, and cytokine secretion. This is consistent with reduced host immune responses in IHD-mut gliomas [62].

A direct link between an IDH mutation and T-cell functions was recently demonstrated. It was shown that tumor cell-derived $(R)-2-\mathrm{HG}$ is taken up by T cells, where it induces perturbation of NFAT 
(nuclear factor of activated T cells) transcriptional activity and polyamine biosynthesis, which results in suppression of T-cell proliferation and activity. IDH1-mut gliomas showed reduced T-cell numbers and altered calcium signaling. Consistently, antitumor immunity to experimental syngeneic IDH1-mut gliomas induced by an IDH1-specific vaccine or checkpoint inhibition was significantly improved by inhibition of the enzymatic function of mutant IDH1 [59].

Blood vessels in glioblastoma are abnormal and display a distinct gene expression signature compared with vessels in normal brain $[63,64]$. Those vascular abnormalities are connected to a high expression of angiogenic factors, including vascular endothelial growth factor (VEGF), transforming growth factor (TGF) $\beta 2$, and pleiotrophin (PTN). In addition to inducing epigenetic deregulation, $(R)-2 \mathrm{HG}$ can regulate the activity of $\alpha$-KG-dependent dioxygenases, specifically EGLN (EGL nine homolog 1) prolyl 4-hydroxylases [65], that are responsible for regulation of HIF1 $\alpha$, which controls angiogenesis. In IDH-mut gliomas (R)-2HG acts as an activator of EGLN prolyl 4-hydroxylases, leading to decreased levels of HIF1 $\alpha$ and reduced expression of genes implicated in hypoxia, and vasculo- and angiogenesis-related signaling such as: VEGFA, PDGF (platelet derived growth factor), or ANGPT2 (angiopoietin-2) [65]. Transcriptomic studies showed that IDH-wt LGGs presented a specific angiogenic gene expression signature, including upregulation of ANGPT2 and SERPINH1 (SERPIN family H), linked to enhanced endothelial cell migration and matrix remodeling, suggesting that these tumors are more angiogenic than IDH-mut LGGs. Transcription factor analysis indicated increased TGF $\beta$ and hypoxia signaling in IDH-wt LGGs. As a consequence, IDH-wt LGG vessels are molecularly distinct from the vasculature of IDH-mut LGGs [66]. All reported data indicated gross differences in composition and functionality of different cells creating the microenvironment of $I D H$-wt and IDH-mut gliomas.

\section{Targeting of Mutant IDH1/2 Gliomas with Isoform-Specific Chemical Inhibitors}

Many preclinical and clinical data validated IDH1/2 as an important target for antitumor drug development. A growing number of studies using cellular and animal models indicate that pharmacological inhibition of mutated IDH1/2 offers therapeutic benefits and there is a rationale for development of isoform-specific inhibitors (Figure 1). In principle, small molecules are designed to bind within the active catalytic site of a mutant $I D H 1 / 2$ and block the conformational change required for the enzyme to convert $\alpha$-KG to 2-HG [67]. Consequently, targeted inhibition of mutated IDH1/2 results in decreased intracellular and serum levels of 2-HG [68,69], followed by reversion of global alterations in an epigenome. Current targeted inhibitors of IDH1 (AG120, IDH305), IDH2 (AG221), and pan-IDH1/2 (AG881) selectively inhibit the mutant IDH activity and induce cell differentiation in in vitro and in vivo models. Preliminary results from phase I clinical trials with IDH inhibitors in patients with advanced hematologic malignancies demonstrated an objective response rate ranging from $31 \%$ to $40 \%$ with durable responses (>1 year) [70]. We briefly summarize the properties of IDH1/2 inhibitors below.

AG-120 is a first-in-class, orally administered, reversible, and highly selective small-molecule inhibitor of mutant IDH1/R132H with half maximal inhibitory concentration $\left(\mathrm{IC}_{50}\right)=40-50 \mathrm{nM}$. AG-120 reduced intracellular levels of 2-HG, inhibited cell proliferation, and released a block of erythropoietin-induced differentiation in human erythroleukemia TF-1 cells harboring IDH1/R132H in vitro and in primary human blast cells cultured ex vivo [68]. AG-120 is currently being evaluated in several clinical trials for the therapy of patients with relapsed or refractory AML, myelodysplastic syndrome, and advanced solid tumors including glioma, chondrosarcoma, and cholangiocarcinoma with a mutant IDH1/R132H (Table 1). Early results from patients with relapsed or refractory AML indicate that monotherapy is well tolerated at doses ranging from 100 to $1200 \mathrm{mg}$, and a maximum tolerated dose was not reached. An overall response rate of $36 \%$ and a complete response rate of $29.5 \%$ were induced [71]. Moreover, dose-escalation clinical trials indicated an overall response rate of 50\% [72]. The plasma 2-HG level in patients with IDH1-mutant AML was reduced almost completely after AG-120 treatment. Preliminary data from a phase I study of patients with IDH1-mut gliomas demonstrated that AG-120 treatment had no dose-limiting toxicity or serious adverse effects [73]. 
AGI-5198 is a small-molecule, highly selective IDH1/R132H inhibitor with a half maximal inhibitory concentration $\mathrm{IC}_{50}=70 \mathrm{nM}$ and $\mathrm{IC}_{50}>100 \mu \mathrm{M}$ for wild-type IDH1 and IDH2 isoforms. It suppressed the production of 2-HG in a dose-dependent manner and significantly inhibited growth of anaplastic oligodendroglioma cells harboring heterozygous IDH1/R132H mutation without influence on IDH1-wt patient-derived glioma cells. AGI-5198 also reduced growth of human IDH1/R132H glioma xenografts in mice and did not impair glioma expressing wild type IDH1, without significant toxicity. AGI-5198 treatment of mice engrafted with IDH1-mutant glioma removed repressive marks via significant reduction of $\mathrm{H} 3 \mathrm{~K} 9$ and $\mathrm{H} 3 \mathrm{~K} 27$ trimethylation at the promoters of genes associated with gliogenic (astrocytic and oligodendrocytic) differentiation, increasing the expression of these genes [74]. AGI-5198 also reduced 2-HG levels in human chondrosarcoma cells that harbor IDH1/R132G and IDH1/R132C mutations in a dose-dependent manner. Moreover, AGI-5198 significantly inhibited colony formation and migration of chondrosarcoma cells, without influence on IDH1-wt human normal chondrocytes, and induced an apoptotic cell death and $\mathrm{G}_{2} / \mathrm{M}$ cell-cycle arrest in human chondrosarcoma cells in vitro [75]. AGI-5198 is yet to enter clinical trials.

BAY-1436032 is a small-molecule, oral inhibitor of pan-mutant IDH1 with IC $_{50}=3-16 \mathrm{nM}$. It blocks 2-HG production and induces myeloid differentiation manifested by morphological changes and upregulated expression of CD14 and CD15 markers in patient-derived IDH1-mut AML cells cultured ex vivo. In mice with implanted AML xenografts, BAY-1436032 decreased the level of 2-HG in serum nearly to the level found in normal tissues, and promoted differentiation of leukemic blast cells which correlated with the prolonged survival. The pan-mutant IDH1 inhibitor affected leukemia stem cells' ability to self-renew with downregulation of stemness-associated genes and upregulation of those associated with myeloid differentiation. Similarly to other IDH-mutant inhibitors, BAY-1436032 affected global histone and DNA methylation levels [76]. The inhibitor entered clinical evaluation for the treatment of patients with advanced solid tumors, including anaplastic glioma, GBM, and intrahepatic cholangiocarcinoma.

FT-2102 is a small-molecule, oral allosteric inhibitor of mutant IDH1 $\left(\mathrm{IC}_{50}=10 \mathrm{nM}\right)$ currently undergoing a clinical study for the treatment of patients with IDH1-mut AML or higher-risk myelodysplastic syndrome, who relapsed or are refractory to a prior therapy or were disqualified for standard treatment. It is used at a dose of $150 \mathrm{mg} /$ daily as monotherapy and in combination with azacitidine [67].

HMS-101 is a small-molecule inhibitor of mutant IDH1 which reduced 2-HG level, affected proliferation and the ERK (extracellular signal-regulated kinase) signaling pathway, and inhibited colony formation of IDH1-mut murine cells and primary AML cells cultured ex vivo without affecting normal bone marrow cells [77]. In a mouse model of leukemia, HMS-101 blocked the production of 2-HG and inhibited proliferation of IDH1-mut cells. It induced cell differentiation, which was correlated with the prolonged survival of mice with IDH1-mut AML cells [78]. HMS-101 is yet to be investigated in patients.

IDH305 is a small-molecule, oral, highly selective, allosteric inhibitor of the mutant IDH1/R132H. IDH305 inhibited 2-HG production and tumor cell proliferation with an $\mathrm{IC}_{50}=24 \mathrm{nM}$, and showed an anticancer activity in IDH1/132H-mut cells in preclinical studies [79]. IDH305 is under clinical evaluation as a single agent or in combination with standard treatments for the therapy of patients with progressive II or III gliomas, low-grade gliomas with measurable 2-HG levels, AML, and other advanced malignancies harboring IDH1/R132H mutations (see summary in Table 1). Early results from clinical studies demonstrated an encouraging anticancer potential of IDH305 and a favorable safety profile in patients with AML harboring mutant IDH1/132H [79].

AGI-6780 is a small-molecule, allosteric inhibitor designed to target the IDH2/R140Q with $\mathrm{IC}_{50}$ $=170 \mathrm{nM}$ and $\mathrm{IC}_{50}>100 \mu \mathrm{M}$ for IDH1/132H. It decreased the level of intracellular and extracellular 2-HG in a dose- and time-dependent manner and induced differentiation of IDH2-mut TF-1 human erythroleukemia cells in vitro and primary human AML cells cultured ex vivo [80]. AGI-6780 reversed DNA hypermethylation within several weeks, whereas histone hypermethylation was removed within several days [81]. AGI-6780 is yet to enter clinical trials. 
AG-221 (enasidenib, CC-90007) is an orally available, reversible, and highly selective inhibitor of the mutant IDH2/R140Q with $\mathrm{IC}_{50}=12 \mathrm{nM}$. AG-221 reduced serum levels of 2-HG and induced myeloid differentiation of AML leukemic blast cells engrafted to immunodeficient mice. AG-221 is currently being evaluated in several clinical trials for the use in advanced hematologic malignancies positive for a mutated IDH2 [69]. AG-221 decreased 2-HG level in marrow, plasma, and urine of xenotransplant mice, and promoted significant survival benefits in a dose-dependent manner [82]. At present, AG-221 is being investigated in clinical trials for the therapy of patients with advanced IDH2-mut hematologic malignancies. Preliminary clinical data indicate that monotherapy with AG-221 resulted in up to a 98\% decrease in 2-HG level in plasma, and the drug was well tolerated [83]. Levels of 2-HG in patients with IDH2-mut AML were lowered to the level in healthy volunteers [84]. AG-221 treatment promoted differentiation of leukemic cells into mature myeloid cells [72], and induced an objective overall response rate of $41 \%$ and a complete response in $28 \%$ patients with AML [72]. An overall response rate in patients with other hematological malignancies was 56\% [72]. Moreover, AG-221 was clinically developed for treatment in combination with standard chemotherapy, and hypomethylating agents in newly diagnosed AML patients [70]. Recently, the inhibitor entered clinical trials for the treatment of patients with advanced solid tumors including glioma, chondrosarcoma, and cholangiocarcinoma with a mutated IDH2 (Table 1).

AG-881 is a small-molecule, orally administered pan-IDH1/2-mutant inhibitor. Preclinical studies indicated that AG-881 blocks both mutated IDH1 and IDH2 proteins with $\mathrm{IC}_{50}=0.04-22 \mathrm{nM}$, decreases the level of 2-HG, and crosses the blood-brain barrier. AG-881 was shown as a full brain-penetrant and, thus, may possibly represent a more effective agent for the therapy of patients with IDH1/2-mut gliomas [67]. A pan-IDH1/2 inhibitor is suggested to be a second-generation drug in IDH-mut cancers [70]. AG-881 is currently being investigated in clinical trials for patients with solid tumors, including gliomas and advanced hematologic malignancies harboring mutated IDH1 and/or IDH2 that progressed prior to treatment with the use of mutant IDH inhibitors [67,70]. As AG-881 recently entered the clinical evaluation in patients, no data reports are yet available (Table 1).

Table 1. A summary of clinical trials with isoform-specific isocitrate dehydrogenase inhibitors.

\begin{tabular}{|c|c|c|c|c|c|c|}
\hline Inhibitor & Target & Cancer & $\begin{array}{l}\text { Current Status of } \\
\text { Clinical Trials }\end{array}$ & $\begin{array}{c}\text { Identifier at } \\
\text { ClinicalTrials.Gov }\end{array}$ & Company & Reference \\
\hline \multirow{4}{*}{ AG-120 } & \multirow{4}{*}{$\begin{array}{l}\text { Mutant } \\
\text { IDH1 }\end{array}$} & $\begin{array}{l}\text { Cholangiocarcinoma, } \\
\text { chondrosarcoma, glioma and } \\
\text { advanced solid tumors }\end{array}$ & Phase I & NCT02073994 & $\begin{array}{c}\text { Agios } \\
\text { Pharmaceuticals } \\
\text { Inc./Celgene } \\
\text { Corporation }\end{array}$ & \multirow{4}{*}[71,73,85]{} \\
\hline & & $\begin{array}{l}\text { Advanced hematologic } \\
\text { malignancies: relapsed or } \\
\text { refractory AML, untreated } \\
\text { AML, other hematologic } \\
\text { malignancies }\end{array}$ & Phase I & NCT02074839 & $\begin{array}{l}\text { Agios } \\
\text { Pharmaceuticals } \\
\text { Inc./Celgene } \\
\text { Corporation }\end{array}$ & \\
\hline & & $\begin{array}{l}\text { Newly diagnosed AML, } \\
\text { untreated AML, AML arising } \\
\text { from MDS, AML arising from } \\
\text { antecedent hematologic } \\
\text { disorder, AML arising after } \\
\text { exposure to genotoxic injury }\end{array}$ & Phase I & NCT02632708 & $\begin{array}{l}\text { Agios } \\
\text { Pharmaceuticals } \\
\text { Inc./Celgene } \\
\text { Corporation }\end{array}$ & \\
\hline & & Newly diagnosed AML & Phase Ib/II & NCT02677922 & $\begin{array}{c}\text { Agios } \\
\text { Pharmaceuticals } \\
\text { Inc./Celgene } \\
\text { Corporation }\end{array}$ & \\
\hline
\end{tabular}


Table 1. Cont

\begin{tabular}{|c|c|c|c|c|c|c|}
\hline Inhibitor & Target & Cancer & $\begin{array}{l}\text { Current Status of } \\
\text { Clinical Trials }\end{array}$ & $\begin{array}{c}\text { Identifier at } \\
\text { ClinicalTrials.Gov }\end{array}$ & Company & Reference \\
\hline \multirow{5}{*}{$\begin{array}{c}\text { AG-221 } \\
\text { (Enasidenib) }\end{array}$} & \multirow{5}{*}{$\begin{array}{l}\text { Mutant } \\
\text { IDH2 }\end{array}$} & $\begin{array}{l}\text { Advanced hematologic } \\
\text { malignancies }\end{array}$ & Phase I/II & NCT01915498 & $\begin{array}{c}\text { Agios } \\
\text { Pharmaceuticals } \\
\text { Inc./Celgene } \\
\text { Corporation }\end{array}$ & \multirow{5}{*}[72,82-85]{} \\
\hline & & $\begin{array}{l}\text { Advanced solid tumors } \\
\text { including glioma, } \\
\text { angioimmunoblastic T-cell } \\
\text { lymphoma, intrahepatic } \\
\text { cholangiocarcinoma } \\
\text { chondrosarcoma }\end{array}$ & Phase I/II & NCT02273739 & $\begin{array}{c}\text { Agios } \\
\text { Pharmaceuticals } \\
\text { Inc./Celgene } \\
\text { Corporation }\end{array}$ & \\
\hline & & Late-stage AML & Phase III & NCT02577406 & $\begin{array}{c}\text { Agios } \\
\text { Pharmaceuticals } \\
\text { Inc./Celgene } \\
\text { Corporation }\end{array}$ & \\
\hline & & $\begin{array}{l}\text { Newly diagnosed AML, } \\
\text { untreated AML, AML arising } \\
\text { from MDS, AML arising from } \\
\text { AHD, AML arising after } \\
\text { exposure to genotoxic injury }\end{array}$ & Phase I & NCT02632708 & $\begin{array}{c}\text { Agios } \\
\text { Pharmaceuticals } \\
\text { Inc./Celgene } \\
\text { Corporation }\end{array}$ & \\
\hline & & Newly diagnosed AML & Phase Ib/II & NCT02677922 & $\begin{array}{c}\text { Agios } \\
\text { Pharmaceuticals } \\
\text { Inc./Celgene } \\
\text { Corporation }\end{array}$ & \\
\hline \multirow[b]{2}{*}{ AG-881 } & \multirow{2}{*}{$\begin{array}{l}\text { Mutant } \\
\text { IDH1 and } \\
\text { IDH2 }\end{array}$} & $\begin{array}{l}\text { Advanced hematologic } \\
\text { malignancies: AML, MDS }\end{array}$ & Phase I & NCT02492737 & $\begin{array}{c}\text { Agios } \\
\text { Pharmaceuticals } \\
\text { Inc./Celgene } \\
\text { Corporation }\end{array}$ & \multirow{2}{*}[67,70]{} \\
\hline & & $\begin{array}{l}\text { Advanced solid tumors: } \\
\text { cholangiocarcinoma } \\
\text { chondrosarcoma, gliomas }\end{array}$ & Phase I & NCT02481154 & $\begin{array}{c}\text { Agios } \\
\text { Pharmaceuticals } \\
\text { Inc./Celgene } \\
\text { Corporation } \\
\end{array}$ & \\
\hline AGI-6780 & $\begin{array}{l}\text { Mutant } \\
\text { IDH2 }\end{array}$ & AML & - & - & $\begin{array}{c}\text { Agios } \\
\text { Pharmaceuticals Inc. }\end{array}$ & {$[80,81]$} \\
\hline AGI-5198 & $\begin{array}{l}\text { Mutant } \\
\text { IDH1 }\end{array}$ & $\begin{array}{c}\text { Chondrosarcoma, low-grade } \\
\text { WHO glioma }\end{array}$ & - & - & Xcess Biosciences Inc. & {$[74,75]$} \\
\hline BAY-1436032 & $\begin{array}{l}\text { Mutant } \\
\text { IDH1 }\end{array}$ & $\begin{array}{l}\text { Advanced solid tumors, } \\
\text { including anaplastic glioma, } \\
\text { glioblastoma, intrahepatic } \\
\text { cholangiocarcinoma }\end{array}$ & Phase I & NCT02746081 & Bayer & {$[76]$} \\
\hline FT-2102 & $\begin{array}{l}\text { Mutant } \\
\text { IDH1 }\end{array}$ & AML, high-risk MDS & Phase I/Ib & NCT02719574 & $\begin{array}{l}\text { Forma Therapeutics } \\
\text { Inc. }\end{array}$ & {$[67]$} \\
\hline HMS-101 & $\begin{array}{l}\text { Mutant } \\
\text { IDH1 }\end{array}$ & AML & - & - & Ascenion $\mathrm{GmnH}$ & {$[78]$} \\
\hline \multirow{4}{*}{ IDH305 } & & II or III WHO glioma & Phase II & NCT02977689 & \multirow{4}{*}{$\begin{array}{c}\text { Novartis AG } \\
\text { Pharmaceuticals }\end{array}$} & \multirow{4}{*}{ [79] } \\
\hline & & Low-grade glioma & Phase II & NCT02987010 & & \\
\hline & $\begin{array}{l}\text { Mutant } \\
\text { IDH1 }\end{array}$ & $\begin{array}{l}\text { AML and advanced solid } \\
\text { tumors including } \\
\text { cholangiocarcinoma and } \\
\text { glioma }\end{array}$ & Phase I & NCT02381886 & & \\
\hline & & AML & Phase I & NCT02826642 & & \\
\hline
\end{tabular}

\section{Development of IDH1-R132H Targeting Peptide Vaccines}

It was demonstrated that an IDH1-R132H protein contains an immunogenic epitope suitable for development of a mutant protein-specific vaccine. A fraction of IDH1-mut glioma patients have isoform-specific antibodies and displayed an IFN- $\gamma$ T-cell response against a mutant IDH1 (mutIDH1) protein. Peptides encompassing the altered region were presented on major histocompatibility complexes (MHC) class II and induced specific CD4 ${ }^{+}$T-helper-1 (TH1) responses against an altered IDH1. Screening of peptide libraries around the altered region of the IDH1-R132H was performed to identify peptides that would induce an interferon- $\gamma($ IFN- $\gamma)$ responses in T cells. A peptide vaccine consisting of a 20-mer peptide was derived from the IDH1-R132H. Peptide vaccination of humanized mice (transgenic for human MHCI and II molecules) with IDH1-R132H tumors resulted in induction of specific antitumor immune responses and restriction of growth of syngeneic IDH1-R132H-expressing tumors. T-cell depletion abrogated the reduction in IDH1-mut tumor growth after IDH1 peptide vaccination [86]. A similar good efficacy of mutIDH1 vaccine was demonstrated in a murine GL261 model, in which immunization of mice bearing mutIDH1/R132H GL261 gliomas was carried out. 
Mice with mIDH1-GL261, but not parental GL261 gliomas, survived longer than controls when treated with mutIDH1 peptides; $25 \%$ of them were cured. Vaccination with peptides resulted in higher counts of peripheral CD8 $8^{+} \mathrm{T}$ cells, higher levels of IFN- $\gamma$, and the presence of anti-mIDH1 antibodies. Intratumoral upregulation of IFN- $\gamma$, Granzyme-B, and Perforin-1, together with downregulation of TGF $\beta 2$ and IL (interleukin)-10 suggested rising antitumor immunity [87]. It was followed by a clinical trial (NOA-16) of the IDH1 peptide vaccine targeting the IDH1-R132H to evaluate the safety and tolerability, as well as immune responses to the vaccine in patients having IDH1-R132H malignant gliomas (https:/ / clinicaltrials.gov/ct2/show/NCT02454634). First reported results showed that NOA-16 demonstrated safety and immunogenicity of a mutant IDH1-R132H peptide vaccine in patients with newly diagnosed IDH1-R132H malignant astrocytomas [88]. These encouraging results provided a strong evidence that a mutation-specific IDH1-R132H vaccine may represent a viable novel therapeutic strategy for IDH1-R132H-mutant tumors [89].

\section{Conclusions}

Several studies provided strong evidence for the oncogenic potential of IDH1/2 mutations, leading to the production of an oncometabolite 2-HG, which alters epigenetic regulation, cancer cell differentiation, and cell metabolism. Depending on associated genomic aberrations and a cellular context, the oncogenic potential of IDH1/2 mutations ranges from an initiating event, which promotes transformation, to a secondary oncogenic event conferring selective advantage to cancer cells. In vitro and in vivo preclinical studies demonstrated that inhibition of mutated IDH1/2 enzymes reduces intracellular 2-HG levels, reverses epigenetic deregulation, and releases the differentiation block in cancer cells. These findings provided a rationale for initiation of preclinical and a few clinical trials evaluating novel, isoform-specific, mutated IDH1/2 inhibitors in cancers with such genomic alteration. Novel inhibitors of mutant IDH1 (AG120, IDH305), IDH2 (AG221), and pan-IDH1/2 (AG881) were developed that selectively inhibit mutant IDH proteins and induce cell differentiation in in vitro and in vivo models. Preliminary results from phase I clinical trials with those inhibitors demonstrated a response rate ranging from $31 \%$ to $40 \%$ with durable responses ( $>1$ year) in patients with advanced hematologic malignancies and a positive activity in solid tumors with IDH mutations, such as cholangiocarcinomas and low-grade gliomas. The mutated IDH1-R132H vaccines were developed and proven to be effective in launching antitumor immunity in preclinical models, which led to initiation of a clinical trial in glioma patients.

Current clinical trials evaluating potential inhibitors in cancers with mutant IDH1/2 are aimed at confirming their safety and tolerability profiles, and clinical activity as a single agent or in combination with standard treatment strategies. AG-120 and AG-221 obtained fast track and orphan drug designations from the United States Food and Drug Administration (FDA). Preliminary results from ongoing clinical trials indicate that pharmacological, small-molecule inhibitors of mutant IDH1/2 have promising activity and efficacy in patients with relapsed and/or refractory cancer disease, as discussed in an elegant recent review [90]. Generally, the treatment was relatively well tolerated and no maximal tolerated doses were reached and those inhibitors showed less toxic adverse effects than standard chemotherapeutic drugs [90].

Author Contributions: All authors equally contributed to writing this manuscript.

Funding: This research was funded by The National Center for Research and Development, STRATEGMED1/ 233574/15/NCBR/2015 “EPTHERON.

Conflicts of Interest: The authors declare no conflicts of interest.

\section{References}

1. Parsons, D.W.; Jones, S.; Zhang, X.; Lin, J.C.; Leary, R.J.; Angenendt, P.; Mankoo, P.; Carter, H.; Siu, I.M.; Gallia, G.L.; et al. An integrated genomic analysis of human glioblastoma multiforme. Science 2008, 321, 1807-1812. [CrossRef] [PubMed] 
2. Mardis, E.R.; Ding, L.; Dooling, D.J.; Larson, D.E.; McLellan, M.D.; Chen, K.; Koboldt, D.C.; Fulton, R.S.; Delehaunty, K.D.; McGrath, S.D.; et al. Recurring mutations found by sequencing an acute myeloid leukemia genome. N. Engl. J. Med. 2009, 361, 1058-1066. [CrossRef] [PubMed]

3. Xu, X.; Zhao, J.; Xu, Z.; Peng, B.; Huang, Q.; Arnold, E.; Ding, J. Structures of human cytosolic NADP-dependent isocitrate dehydrogenase reveal a novel self-regulatory mechanism of activity. J. Biol. Chem. 2004, 279, 33946-33957. [CrossRef] [PubMed]

4. Henderson, N.S. Isozymes of Isocitrate Dehydrogenase: Subunit Structure and Intracellular Location. J. Exp. Zool. 1965, 158, 263-273. [CrossRef]

5. Reitman, Z.J.; Yan, H. Isocitrate dehydrogenase 1 and 2 mutations in cancer: Alterations at a crossroads of cellular metabolism. J. Natl. Cancer Inst. 2010, 102, 932-941. [CrossRef] [PubMed]

6. Koh, H.J.; Lee, S.M.; Son, B.G.; Lee, S.H.; Ryoo, Z.Y.; Chang, K.T.; Park, J.W.; Park, D.C.; Song, B.J.; Veech, R.L.; et al. Cytosolic $\mathrm{NADP}^{+}$-dependent isocitrate dehydrogenase plays a key role in lipid metabolism. J. Biol. Chem. 2004, 279, 39968-39974. [CrossRef] [PubMed]

7. Minard, K.I.; McAlister-Henn, L. Dependence of peroxisomal beta-oxidation on cytosolic sources of NADPH. J. Biol. Chem. 1999, 274, 3402-3406. [CrossRef] [PubMed]

8. Lee, S.M.; Koh, H.J.; Park, D.C.; Song, B.J.; Huh, T.L.; Park, J.W. Cytosolic NADP(+)-dependent isocitrate dehydrogenase status modulates oxidative damage to cells. Free Radic. Biol. Med. 2002, 32, 1185-1196. [CrossRef]

9. Metellus, P.; Colin, C.; Taieb, D.; Guedj, E.; Nanni-Metellus, I.; de Paula, A.M.; Colavolpe, C.; Fuentes, S.; Dufour, H.; Barrie, M.; et al. IDH mutation status impact on in vivo hypoxia biomarkers expression: New insights from a clinical, nuclear imaging and immunohistochemical study in 33 glioma patients. J. Neurooncol. 2011, 105, 591-600. [CrossRef]

10. Bleeker, F.E.; Atai, N.A.; Lamba, S.; Jonker, A.; Rijkeboer, D.; Bosch, K.S.; Tigchelaar, W.; Troost, D.; Vandertop, W.P.; Bardelli, A.; et al. The prognostic IDH1(R132) mutation is associated with reduced NADP+-dependent IDH activity in glioblastoma. Acta Neuropathol. 2010, 119, 487-494. [CrossRef]

11. Metallo, C.M.; Gameiro, P.A.; Bell, E.L.; Mattaini, K.R.; Yang, J.; Hiller, K.; Jewell, C.M.; Johnson, Z.R.; Irvine, D.J.; Guarente, L.; et al. Reductive glutamine metabolism by IDH1 mediates lipogenesis under hypoxia. Nature 2011, 481, 380-384. [CrossRef] [PubMed]

12. Zhao, S.; Lin, Y.; Xu, W.; Jiang, W.; Zha, Z.; Wang, P.; Yu, W.; Li, Z.; Gong, L.; Peng, Y.; et al. Glioma-derived mutations in IDH1 dominantly inhibit IDH1 catalytic activity and induce HIF-1alpha. Science 2009, 324, 261-265. [CrossRef] [PubMed]

13. Ward, P.S.; Patel, J.; Wise, D.R.; Abdel-Wahab, O.; Bennett, B.D.; Coller, H.A.; Cross, J.R.; Fantin, V.R.; Hedvat, C.V.; Perl, A.E.; et al. The common feature of leukemia-associated IDH1 and IDH2 mutations is a neomorphic enzyme activity converting alpha-ketoglutarate to 2-hydroxyglutarate. Cancer Cell 2010, 17, 225-234. [CrossRef] [PubMed]

14. Dang, L.; White, D.W.; Gross, S.; Bennett, B.D.; Bittinger, M.A.; Driggers, E.M.; Fantin, V.R.; Jang, H.G.; Jin, S.; Keenan, M.C.; et al. Cancer-associated IDH1 mutations produce 2-hydroxyglutarate. Nature 2009, 462, 739-744. [CrossRef] [PubMed]

15. Chowdhury, R.; Yeoh, K.K.; Tian, Y.M.; Hillringhaus, L.; Bagg, E.A.; Rose, N.R.; Leung, I.K.; Li, X.S.; Woon, E.C.; Yang, M.; et al. The oncometabolite 2-hydroxyglutarate inhibits histone lysine demethylases. EMBO Rep. 2011, 12, 463-469. [CrossRef] [PubMed]

16. Hou, H.; Yu, H. Structural insights into histone lysine demethylation. Curr. Opin. Struct. Biol. 2010, 20, 739-748. [CrossRef] [PubMed]

17. Turcan, S.; Rohle, D.; Goenka, A.; Walsh, L.A.; Fang, F.; Yilmaz, E.; Campos, C.; Fabius, A.W.; Lu, C.; Ward, P.S.; et al. IDH1 mutation is sufficient to establish the glioma hypermethylator phenotype. Nature 2012, 483, 479-483. [CrossRef]

18. Xu, W.; Yang, H.; Liu, Y.; Yang, Y.; Wang, P.; Kim, S.H.; Ito, S.; Yang, C.; Wang, P.; Xiao, M.T.; et al. Oncometabolite 2-hydroxyglutarate is a competitive inhibitor of alpha-ketoglutarate-dependent dioxygenases. Cancer Cell 2011, 19, 17-30. [CrossRef]

19. Liu, Y.; Jiang, W.; Liu, J.; Zhao, S.; Xiong, J.; Mao, Y.; Wang, Y. IDH1 mutations inhibit multiple alpha-ketoglutarate-dependent dioxygenase activities in astroglioma. J. Neurooncol. 2012, 109, 253-260. [CrossRef] 
20. Kickingereder, P.; Sahm, F.; Radbruch, A.; Wick, W.; Heiland, S.; Deimling, A.; Bendszus, M.; Wiestler, B. IDH mutation status is associated with a distinct hypoxia/angiogenesis transcriptome signature which is non-invasively predictable with rCBV imaging in human glioma. Sci. Rep. 2015, 5, 16238. [CrossRef]

21. Reitman, Z.J.; Jin, G.; Karoly, E.D.; Spasojevic, I.; Yang, J.; Kinzler, K.W.; He, Y.; Bigner, D.D.; Vogelstein, B.; Yan, H. Profiling the effects of isocitrate dehydrogenase 1 and 2 mutations on the cellular metabolome. Proc. Natl. Acad. Sci. USA 2011, 108, 3270-3275. [CrossRef] [PubMed]

22. Ye, D.; Guan, K.L.; Xiong, Y. Metabolism, Activity, and Targeting of D- and L-2-Hydroxyglutarates. Trends Cancer 2018, 4, 151-165. [CrossRef] [PubMed]

23. Calvert, A.E.; Chalastanis, A.; Wu, Y.; Hurley, L.A.; Kouri, F.M.; Bi, Y.; Kachman, M.; May, J.L.; Bartom, E.; Hua, Y.; et al. Cancer-Associated IDH1 Promotes Growth and Resistance to Targeted Therapies in the Absence of Mutation. Cell Rep. 2017, 19, 1858-1873. [CrossRef] [PubMed]

24. Louis, D.N.; Perry, A.; Reifenberger, G.; von Deimling, A.; Figarella-Branger, D.; Cavenee, W.K.; Ohgaki, H.; Wiestler, O.D.; Kleihues, P.; Ellison, D.W. The 2016 World Health Organization Classification of Tumors of the Central Nervous System: A summary. Acta Neuropathol. 2016, 131, 803-820. [CrossRef] [PubMed]

25. Noushmehr, H.; Weisenberger, D.J.; Diefes, K.; Phillips, H.S.; Pujara, K.; Berman, B.P.; Pan, F.; Pelloski, C.E.; Sulman, E.P.; Bhat, K.P.; et al. Identification of a CpG island methylator phenotype that defines a distinct subgroup of glioma. Cancer Cell 2010, 17, 510-522. [CrossRef] [PubMed]

26. Ceccarelli, M.; Barthel, F.P.; Malta, T.M.; Sabedot, T.S.; Salama, S.R.; Murray, B.A.; Morozova, O.; Newton, Y.; Radenbaugh, A.; Pagnotta, S.M.; et al. Molecular Profiling Reveals Biologically Discrete Subsets and Pathways of Progression in Diffuse Glioma. Cell 2016, 164, 550-563. [CrossRef] [PubMed]

27. Korshunov, A.; Casalini, B.; Chavez, L.; Hielscher, T.; Sill, M.; Ryzhova, M.; Sharma, T.; Schrimpf, D.; Stichel, D.; Capper, D.; et al. Integrated molecular characterization of IDH-mutant glioblastomas. Neuropathol. Appl. Neurobiol. 2018. [CrossRef] [PubMed]

28. Madala, H.R.; Punganuru, S.R.; Arutla, V.; Misra, S.; Thomas, T.J.; Srivenugopal, K.S. Beyond Brooding on Oncometabolic Havoc in IDH-Mutant Gliomas and AML: Current and Future Therapeutic Strategies. Cancers 2018, 10, 49. [CrossRef]

29. Yan, H.; Parsons, D.W.; Jin, G.; McLendon, R.; Rasheed, B.A.; Yuan, W.; Kos, I.; Batinic-Haberle, I.; Jones, S.; Riggins, G.J.; et al. IDH1 and IDH2 mutations in gliomas. N. Engl. J. Med. 2009, 360, 765-773. [CrossRef]

30. van den Bent, M.J.; Dubbink, H.J.; Marie, Y.; Brandes, A.A.; Taphoorn, M.J.; Wesseling, P.; Frenay, M.; Tijssen, C.C.; Lacombe, D.; Idbaih, A.; et al. IDH1 and IDH2 mutations are prognostic but not predictive for outcome in anaplastic oligodendroglial tumors: A report of the European Organization for Research and Treatment of Cancer Brain Tumor Group. Clin. Cancer Res. 2010, 16, 1597-1604. [CrossRef]

31. Ichimura, K.; Pearson, D.M.; Kocialkowski, S.; Backlund, L.M.; Chan, R.; Jones, D.T.; Collins, V.P. IDH1 mutations are present in the majority of common adult gliomas but rare in primary glioblastomas. Neuro-Oncology 2009, 11, 341-347. [CrossRef] [PubMed]

32. Sturm, D.; Pfister, S.M.; Jones, D.T.W. Pediatric Gliomas: Current Concepts on Diagnosis, Biology, and Clinical Management. J. Clin. Oncol. 2017, 35, 2370-2377. [CrossRef] [PubMed]

33. Waitkus, M.S.; Diplas, B.H.; Yan, H. Isocitrate dehydrogenase mutations in gliomas. Neuro-Oncology 2016, 18, 16-26. [CrossRef] [PubMed]

34. Esteller, M.; Garcia-Foncillas, J.; Andion, E.; Goodman, S.N.; Hidalgo, O.F.; Vanaclocha, V.; Baylin, S.B.; Herman, J.G. Inactivation of the DNA-repair gene MGMT and the clinical response of gliomas to alkylating agents. N. Engl. J. Med. 2000, 343, 1350-1354. [CrossRef] [PubMed]

35. Balss, J.; Meyer, J.; Mueller, W.; Korshunov, A.; Hartmann, C.; von Deimling, A. Analysis of the IDH1 codon 132 mutation in brain tumors. Acta Neuropathol. 2008, 116, 597-602. [CrossRef] [PubMed]

36. Sarmiento, J.M.; Mukherjee, D.; Black, K.L.; Fan, X.; Hu, J.L.; Nuno, M.A.; Patil, C.G. Do Long-Term Survivor Primary Glioblastoma Patients Harbor IDH1 Mutations? J. Neurol. Surg. A Cent. Eur. Neurosurg. 2016, 77, 195-200. [CrossRef] [PubMed]

37. Amelot, A.; De Cremoux, P.; Quillien, V.; Polivka, M.; Adle-Biassette, H.; Lehmann-Che, J.; Francoise, L.; Carpentier, A.F.; George, B.; Mandonnet, E.; et al. IDH-Mutation Is a Weak Predictor of Long-Term Survival in Glioblastoma Patients. PLoS ONE 2015, 10, e0130596. [CrossRef] [PubMed]

38. Iwadate, Y.; Matsutani, T.; Hirono, S.; Ikegami, S.; Shinozaki, N.; Saeki, N. IDH1 mutation is prognostic for diffuse astrocytoma but not low-grade oligodendrogliomas in patients not treated with early radiotherapy. J. Neurooncol. 2015, 124, 493-500. [CrossRef] 
39. Mellai, M.; Annovazzi, L.; Senetta, R.; Dell'Aglio, C.; Mazzucco, M.; Cassoni, P.; Schiffer, D. Diagnostic revision of 206 adult gliomas (including 40 oligoastrocytomas) based on ATRX, IDH1/2 and 1p/19q status. J. Neurooncol. 2017, 131, 213-222. [CrossRef]

40. Li, H.; Li, J.; Cheng, G.; Zhang, J.; Li, X. IDH mutation and MGMT promoter methylation are associated with the pseudoprogression and improved prognosis of glioblastoma multiforme patients who have undergone concurrent and adjuvant temozolomide-based chemoradiotherapy. Clin. Neurol. Neurosurg. 2016, 151, 31-36. [CrossRef]

41. Chen, N.; Yu, T.; Gong, J.; Nie, L.; Chen, X.; Zhang, M.; Xu, M.; Tan, J.; Su, Z.; Zhong, J.; et al. IDH1/2 gene hotspot mutations in central nervous system tumours: Analysis of 922 Chinese patients. Pathology 2016, 48, 675-683. [CrossRef] [PubMed]

42. Nakae, S.; Sasaki, H.; Hayashi, S.; Hattori, N.; Kumon, M.; Nishiyama, Y.; Adachi, K.; Nagahisa, S.; Hayashi, T.; Inamasu, J.; et al. PCR-Based Simple Subgrouping Is Validated for Classification of Gliomas and Defines Negative Prognostic Copy Number Aberrations in IDH Mutant Gliomas. PLoS ONE 2015, 10, e0142750. [CrossRef] [PubMed]

43. Schiffgens, S.; Wilkens, L.; Brandes, A.A.; Meier, T.; Franceschi, E.; Ermani, M.; Hartmann, C.; Sandalcioglu, I.E.; Dumitru, C.A. Sex-specific clinicopathological significance of novel (Frizzled-7) and established (MGMT, IDH1) biomarkers in glioblastoma. Oncotarget 2016, 7, 55169-55180. [CrossRef] [PubMed]

44. Yang, Y.; Mao, Q.; Wang, X.; Liu, Y.; Mao, Y.; Zhou, Q.; Luo, J. An analysis of 170 glioma patients and systematic review to investigate the association between IDH-1 mutations and preoperative glioma-related epilepsy. J. Clin. Neurosci. 2016, 31, 56-62. [CrossRef] [PubMed]

45. Li, Y.; Shan, X.; Wu, Z.; Wang, Y.; Ling, M.; Fan, X. IDH1 mutation is associated with a higher preoperative seizure incidence in low-grade glioma: A systematic review and meta-analysis. Seizure 2018, 55, 76-82. [CrossRef] [PubMed]

46. Gieryng, A.; Pszczolkowska, D.; Walentynowicz, K.A.; Rajan, W.D.; Kaminska, B. Immune microenvironment of gliomas. Lab. Investig. 2017, 97, 498-518. [CrossRef] [PubMed]

47. Hambardzumyan, D.; Gutmann, D.H.; Kettenmann, H. The role of microglia and macrophages in glioma maintenance and progression. Nat. Neurosci. 2016, 19, 20-27. [CrossRef]

48. Kim, Y.H.; Jung, T.Y.; Jung, S.; Jang, W.Y.; Moon, K.S.; Kim, I.Y.; Lee, M.C.; Lee, J.J. Tumour-infiltrating T-cell subpopulations in glioblastomas. Br. J. Neurosurg. 2012, 26, 21-27. [CrossRef] [PubMed]

49. Lohr, J.; Ratliff, T.; Huppertz, A.; Ge, Y.; Dictus, C.; Ahmadi, R.; Grau, S.; Hiraoka, N.; Eckstein, V.; Ecker, R.C.; et al. Effector T-cell infiltration positively impacts survival of glioblastoma patients and is impaired by tumor-derived TGF-beta. Clin. Cancer Res. 2011, 17, 4296-4308. [CrossRef] [PubMed]

50. Han, S.; Zhang, C.; Li, Q.; Dong, J.; Liu, Y.; Huang, Y.; Jiang, T.; Wu, A. Tumour-infiltrating CD4(+) and CD8(+) lymphocytes as predictors of clinical outcome in glioma. Br. J. Cancer 2014, 110, 2560-2568. [CrossRef] [PubMed]

51. Mu, L.; Yang, C.; Gao, Q.; Long, Y.; Ge, H.; DeLeon, G.; Jin, L.; Chang, Y.E.; Sayour, E.J.; Ji, J.; et al. CD4+ and Perivascular Foxp3+ T Cells in Glioma Correlate with Angiogenesis and Tumor Progression. Front. Immunol. 2017, 8, 1451. [CrossRef] [PubMed]

52. Preusser, M.; Lim, M.; Hafler, D.A.; Reardon, D.A.; Sampson, J.H. Prospects of immune checkpoint modulators in the treatment of glioblastoma. Nat. Rev. Neurol. 2015, 11, 504-514. [CrossRef] [PubMed]

53. Fong, B.; Jin, R.; Wang, X.; Safaee, M.; Lisiero, D.N.; Yang, I.; Li, G.; Liau, L.M.; Prins, R.M. Monitoring of regulatory $\mathrm{T}$ cell frequencies and expression of CTLA-4 on T cells, before and after DC vaccination, can predict survival in GBM patients. PLoS ONE 2012, 7, e32614. [CrossRef]

54. Nduom, E.K.; Wei, J.; Yaghi, N.K.; Huang, N.; Kong, L.Y.; Gabrusiewicz, K.; Ling, X.; Zhou, S.; Ivan, C.; Chen, J.Q.; et al. PD-L1 expression and prognostic impact in glioblastoma. Neuro-Oncology 2016, 18, $195-205$. [CrossRef] [PubMed]

55. Kohanbash, G.; Carrera, D.A.; Shrivastav, S.; Ahn, B.J.; Jahan, N.; Mazor, T.; Chheda, Z.S.; Downey, K.M.; Watchmaker, P.B.; Beppler, C.; et al. Isocitrate dehydrogenase mutations suppress STAT1 and CD8+ T cell accumulation in gliomas. J. Clin. Investig. 2017, 127, 1425-1437. [CrossRef] [PubMed]

56. Garber, S.T.; Hashimoto, Y.; Weathers, S.P.; Xiu, J.; Gatalica, Z.; Verhaak, R.G.; Zhou, S.; Fuller, G.N.; Khasraw, M.; de Groot, J.; et al. Immune checkpoint blockade as a potential therapeutic target: Surveying CNS malignancies. Neuro-Oncology 2016, 18, 1357-1366. [CrossRef] [PubMed] 
57. Berghoff, A.S.; Kiesel, B.; Widhalm, G.; Wilhelm, D.; Rajky, O.; Kurscheid, S.; Kresl, P.; Wohrer, A.; Marosi, C.; Hegi, M.E.; et al. Correlation of immune phenotype with IDH mutation in diffuse glioma. Neuro-Oncology 2017, 19, 1460-1468. [CrossRef]

58. Pratt, D.; Dominah, G.; Lobel, G.; Obungu, A.; Lynes, J.; Sanchez, V.; Adamstein, N.; Wang, X.; Edwards, N.A.; $\mathrm{Wu}, \mathrm{T}$; ; et al. Programmed Death Ligand 1 Is a Negative Prognostic Marker in Recurrent Isocitrate Dehydrogenase-Wildtype Glioblastoma. Neurosurgery 2018. [CrossRef]

59. Bunse, L.; Pusch, S.; Bunse, T.; Sahm, F.; Sanghvi, K.; Friedrich, M.; Alansary, D.; Sonner, J.K.; Green, E.; Deumelandt, K.; et al. Suppression of antitumor T cell immunity by the oncometabolite (R)-2-hydroxyglutarate. Nat. Med. 2018, 24, 1192-1203. [CrossRef]

60. Amankulor, N.M.; Kim, Y.; Arora, S.; Kargl, J.; Szulzewsky, F.; Hanke, M.; Margineantu, D.H.; Rao, A.; Bolouri, H.; Delrow, J.; et al. Mutant IDH1 regulates the tumor-associated immune system in gliomas. Genes Dev. 2017, 31, 774-786. [CrossRef]

61. Luoto, S.; Hermelo, I.; Vuorinen, E.M.; Hannus, P.; Kesseli, J.; Nykter, M.; Granberg, K.J. Computational Characterization of Suppressive Immune Microenvironments in Glioblastoma. Cancer Res. 2018, 78, 5574-5585. [CrossRef] [PubMed]

62. Zhang, L.; Sorensen, M.D.; Kristensen, B.W.; Reifenberger, G.; McIntyre, T.M.; Lin, F. D-2-Hydroxyglutarate Is an Intercellular Mediator in IDH-Mutant Gliomas Inhibiting Complement and T Cells. Clin. Cancer Res. 2018, 24, 5381-5391. [CrossRef] [PubMed]

63. Dieterich, L.C.; Mellberg, S.; Langenkamp, E.; Zhang, L.; Zieba, A.; Salomaki, H.; Teichert, M.; Huang, H.; Edqvist, P.H.; Kraus, T.; et al. Transcriptional profiling of human glioblastoma vessels indicates a key role of VEGF-A and TGFbeta2 in vascular abnormalization. J. Pathol. 2012, 228, 378-390. [CrossRef] [PubMed]

64. Pen, A.; Moreno, M.J.; Martin, J.; Stanimirovic, D.B. Molecular markers of extracellular matrix remodeling in glioblastoma vessels: Microarray study of laser-captured glioblastoma vessels. Glia 2007, 55, 559-572. [CrossRef] [PubMed]

65. Koivunen, P.; Lee, S.; Duncan, C.G.; Lopez, G.; Lu, G.; Ramkissoon, S.; Losman, J.A.; Joensuu, P.; Bergmann, U.; Gross, S.; et al. Transformation by the (R)-enantiomer of 2-hydroxyglutarate linked to EGLN activation. Nature 2012, 483, 484-488. [CrossRef] [PubMed]

66. Zhang, L.; He, L.; Lugano, R.; Roodakker, K.; Bergqvist, M.; Smits, A.; Dimberg, A. IDH mutation status is associated with distinct vascular gene expression signatures in lower-grade gliomas. Neuro-Oncology 2018, 20, 1505-1516. [CrossRef] [PubMed]

67. Medeiros, B.C.; Fathi, A.T.; DiNardo, C.D.; Pollyea, D.A.; Chan, S.M.; Swords, R. Isocitrate dehydrogenase mutations in myeloid malignancies. Leukemia 2017, 31, 272-281. [CrossRef]

68. Hansen, E.; Quivoron, C.; Straley, K.; Lemieux, R.M.; Popovici-Muller, J.; Sadrzadeh, H.; Fathi, A.T.; Gliser, C.; David, M.; Saada, V.; et al. AG-120, an Oral, Selective, First-in-Class, Potent Inhibitor of Mutant IDH1, Reduces Intracellular 2HG and Induces Cellular Differentiation in TF-1 R132H Cells and Primary Human IDH1 Mutant AML Patient Samples Treated Ex Vivo. Blood 2014, 124, 3734.

69. Quivoron, C.; David, M.; Straley, K.; Travins, J.; Kim, H.; Chen, Y.; Zhu, D.; Saada, V.; Bawa, O.; Opolon, P.; et al. AG-221, an Oral, Selective, First-in-Class, Potent IDH2-R140Q Mutant Inhibitor, Induces Differentiation in a Xenotransplant Model. Blood 2014, 124, 3735.

70. Fujii, T.; Khawaja, M.R.; DiNardo, C.D.; Atkins, J.T.; Janku, F. Targeting isocitrate dehydrogenase (IDH) in cancer. Discov. Med. 2016, 21, 373-380.

71. DiNardo, C.; de Botton, S.; Pollyea, D.A.; Stein, E.M.; Fathi, A.T.; Roboz, G.J.; Collins, R.; Swords, R.T.; Flinn, I.W.; Altman, J.K.; et al. Molecular Profiling and Relationship with Clinical Response in Patients with IDH1 Mutation-Positive Hematologic Malignancies Receiving AG-120, a First-in-Class Potent Inhibitor of Mutant IDH1, in Addition to Data from the Completed Dose Escalation Portion of the Phase 1 Study. Blood 2015, 126, 1306.

72. Stein, E.M.; DiNardo, C.; Altman, J.K.; Collins, R.; DeAngelo, D.J.; Kantarjian, H.M.; Sekeres, M.A.; Fathi, A.T.; Flinn, I.W.; Frankel, A.E.; et al. Safety and Efficacy of AG-221, a Potent Inhibitor of Mutant IDH2 That Promotes Differentiation of Myeloid Cells in Patients with Advanced Hematologic Malignancies: Results of a Phase 1/2 Trial. Blood 2015, 126, 323. 
73. Burris, H.; Mellinghoff, I.; Maher, E.; Wen, P.; Beeram, M.; Touat, M.; Faris, J.; Azad, N.; Cloughesy, T.; Gore, L.; et al. The first reported results of AG-120, a first-in-class, potent inhibitor of the IDH1 mutant protein, in a Phase I study of patients with advanced IDH1-mutant solid tumors, including gliomas. In Proceedings of the AACR-NCI-EORTC International Conference: Molecular Targets and Cancer Therapeutics, Boston, MA, USA, 5-9 November 2015; Mol Cancer Ther: Philadelphia, PA, USA, 2015; Abstract PL04-05.

74. Rohle, D.; Popovici-Muller, J.; Palaskas, N.; Turcan, S.; Grommes, C.; Campos, C.; Tsoi, J.; Clark, O.; Oldrini, B.; Komisopoulou, E.; et al. An inhibitor of mutant IDH1 delays growth and promotes differentiation of glioma cells. Science 2013, 340, 626-630. [CrossRef] [PubMed]

75. Li, L.; Paz, A.C.; Wilky, B.A.; Johnson, B.; Galoian, K.; Rosenberg, A.; Hu, G.; Tinoco, G.; Bodamer, O.; Trent, J.C. Treatment with a Small Molecule Mutant IDH1 Inhibitor Suppresses Tumorigenic Activity and Decreases Production of the Oncometabolite 2-Hydroxyglutarate in Human Chondrosarcoma Cells. PLOS ONE 2015, 10, e0133813. [CrossRef] [PubMed]

76. Heuser, M.; Herbst, L.; Pusch, S.; Klett, L.; Goparaju, R.; Stichel, D.; Kaulfuss, S.; Panknin, O.; Zimmermann, K.; Toschi, L.; et al. Pan-Mutant-IDH1 Inhibitor Bay-1436032 Is Highly Effective Against Human IDH1 Mutant Acute Myeloid Leukemia In Vivo. Blood 2016, 128, 745.

77. Chaturvedi, A.; Araujo Cruz, M.M.; Jyotsana, N.; Sharma, A.; Yun, H.; Görlich, K.; Wichmann, M.; Schwarzer, A.; Preller, M.; Thol, F.; et al. Mutant IDH1 promotes leukemogenesis in vivo and can be specifically targeted in human AML. Blood 2013, 122, 2877-2887. [CrossRef] [PubMed]

78. Chaturvedi, A.; Araujo Cruz, M.M.; Goparaju, R.; Jyotsana, N.; Baehre, H.; Goerlich, K.; Schottmann, R.; Preller, M.; Struys, E.A.; Kloos, A.; et al. A Novel Inhibitor of Mutant IDH1 Induces Differentiation in Vivo and Prolongs Survival in a Mouse Model of Leukemia. Blood 2014, 124, 3598.

79. DiNardo, C.D.; Schimmer, A.D.; Yee, K.W.L.; Hochhaus, A.; Kraemer, A.; Carvajal, R.D.; Janku, F.; Bedard, P.; Carpio, C.; Wick, A.; et al. A Phase I Study of IDH305 in Patients with Advanced Malignancies Including Relapsed/Refractory AML and MDS That Harbor IDH1R132 Mutations. Blood 2016, 128, 1073.

80. Wang, F.; Travins, J.; DeLaBarre, B.; Penard-Lacronique, V.; Schalm, S.; Hansen, E.; Straley, K.; Kernytsky, A.; Liu, W.; Gliser, C.; et al. Targeted inhibition of mutant IDH2 in leukemia cells induces cellular differentiation. Science 2013, 340, 622-626. [CrossRef]

81. Kernytsky, A.; Wang, F.; Hansen, E.; Schalm, S.; Straley, K.; Gliser, C.; Yang, H.; Travins, J.; Murray, S.; Dorsch, M.; et al. IDH2 mutation-induced histone and DNA hypermethylation is progressively reversed by small-molecule inhibition. Blood 2015, 125, 296-303. [CrossRef]

82. Wang, F.; Travins, J.; Chen, Y.; Yang, H.; Straley, K.; Choe, S.; Dorsch, M.; Schenkein, D.P.; Agresta, S.; Biller, S.; et al. AG-221 Offers a Survival Advantage in a Primary Human IDH2 Mutant AML Xenograft Model. Blood 2013, 122, 240.

83. Stein, E.; Altman, J.K.; Collins, R.; DeAngelo, D.; Fathi, A.; Flinn, I.; Frankel, A.; Levine, R.; Medeiros, B.; et al. AG-221, an oral, selective, first-in-class, potent inhibitor of the IDH2 mutant enzyme, induced durable responses in a phase 1 study of IDH2 mutation-positive advanced hematologic malignancies. Blood 2014, $124,115$.

84. Fan, B.; Chen, Y.; Wang, F.; Yen, K.; Utley, L.; Almon, C.; Straley, K.; Attar, E.; Bowden, C.; Biller, S.; et al. Pharmacokinetic/pharmacodynamic (PK/PD) evaluation of AG-221, a potent mutant IDH2 inhibitor, from a phase 1 trial of patients with IDH2-mutation positive hematologic malignancies. Haematologica 2015, 100 (Suppl. 1), E948.

85. de Botton, S. Targeting isocitrate dehydrogenase-1 (IDH1) and IDH2 mutations. Clinical results in advanced hematologic malignancies. Ann. Oncol. 2015, 26, Abstract ii15. [CrossRef]

86. Schumacher, T.; Bunse, L.; Pusch, S.; Sahm, F.; Wiestler, B.; Quandt, J.; Menn, O.; Osswald, M.; Oezen, I.; Ott, M.; et al. A vaccine targeting mutant IDH1 induces antitumour immunity. Nature 2014, 512, 324-327. [CrossRef] [PubMed]

87. Pellegatta, S.; Valletta, L.; Corbetta, C.; Patane, M.; Zucca, I.; Riccardi Sirtori, F.; Bruzzone, M.G.; Fogliatto, G.; Isacchi, A.; Pollo, B.; et al. Effective immuno-targeting of the IDH1 mutation R132H in a murine model of intracranial glioma. Acta Neuropathol. Commun. 2015, 3, 4. [CrossRef] [PubMed] 
88. Platten, M.; Schilling, D.; Bunse, L.; Wick, A.; Bunse, T.; Riehl, D.; Green, E.; Sanghvi, K.; Karapanagiotou-Schenkel, I.; Harting, I.; et al. ATIM-33. NOA-16: A first-in-man multicenter phase I clinical trial of the german neurooncology working group evaluating a mutation-specific peptide vaccine targeting IDH1R132H in patients with newly diagnosed malignant astrocytomas. Neuro-Oncology 2018, 20, vi8-vi9. [CrossRef]

89. Friedrich, M.; Bunse, L.; Wick, W.; Platten, M. Perspectives of immunotherapy in isocitrate dehydrogenasemutant gliomas. Curr. Opin. Oncol. 2018, 30, 368-374. [CrossRef] [PubMed]

90. Ma, T.; Zou, F.; Pusch, S.; Xu, Y.; von Deimling, A.; Zha, X. Inhibitors of Mutant Isocitrate Dehydrogenases 1 and 2 (mIDH1/2): An Update and Perspective. J. Med. Chem. 2018, 61, 8981-9003. [CrossRef]

C 2019 by the authors. Licensee MDPI, Basel, Switzerland. This article is an open access article distributed under the terms and conditions of the Creative Commons Attribution (CC BY) license (http://creativecommons.org/licenses/by/4.0/). 